\title{
A discussion on generalized almost contractions via rational expressions in partially ordered metric spaces
}

Zead Mustafa ${ }^{1}$, Erdal Karapınar ${ }^{2,3^{*}}$ and Hassen Aydi4, ${ }^{4}$

\section{"Correspondence:}

erdalkarapinar@yahoo.com; ekarapinar@atilim.edu.tr

${ }^{2}$ Department of Mathematics, Atilim University, Incek, Ankara 06836, Turkey

${ }^{3}$ Nonlinear Analysis and Applied Mathematics Research Group (NAAM), King Abdulaziz University, Jeddah, Saudi Arabia

Full list of author information is available at the end of the article

\begin{abstract}
The main purpose of this paper is to give some fixed point results for mappings involving generalized $(\phi, \psi)$-contractions in partially ordered metric spaces. Our results generalize, extend, and unify several well-known comparable results in the literature (Jaggi in Indian J. Pure Appl. Math. 8(2):223-230, 1977, Harjani et al. in Nonlinear Anal. 71:3403-3410, 2009, Luong and Thuan in Fixed Point Theory Appl. 2011:46, 2011). The presented results are supported by three illustrative examples. MSC: 46N40; 47H10; 54H25; 46T99
\end{abstract}

Keywords: ordered set; metric space; fixed point

\section{Introduction and preliminaries}

The Banach contraction mapping principle [1] is one of the pivotal results of analysis. It is widely considered as the source of metric fixed point theory. Also, its significance lies in its application in a vast number of branches of mathematics. Generalizations of this principle have been investigated heavily (see Jaggi [2], Harjani et al. [3], Luong and Thuan [4]). In particular, in 1977, Jaggi [2] proved the following theorem satisfying a contractive condition of a rational type.

Theorem 1 Let $(X, d)$ be a complete metric space. Let $T: X \rightarrow X$ be a continuous mapping such that

$$
d(T x, T y) \leq \alpha \frac{d(x, T x) d(y, T y)}{d(x, y)}+\beta d(x, y)
$$

for all distinct points $x, y \in X$ where $\alpha, \beta \in[0,1)$ with $\alpha+\beta<1$. Then $T$ has a unique fixed point.

Existence of fixed point in partially ordered sets has been recently studied in [3-53].

Recently, Harjani et al. [3] proved the ordered version of Theorem 1. Very recently, Luong and Thuan [4] generalized the results of [3] and proved the following.

○2014 Mustafa et al.; licensee Springer. This is an Open Access article distributed under the terms of the Creative Commons Attribution License (http://creativecommons.org/licenses/by/2.0), which permits unrestricted use, distribution, and reproduction in any medium, provided the original work is properly cited. 
Theorem 2 Let $(X, \leq)$ be a partially ordered set. Suppose there exists a metric $d$ such that $(X, d)$ is a metric space. Let $T: X \rightarrow X$ be a non-decreasing mapping such that

$$
d(T x, T y) \leq M(x, y)-\psi(M(x, y))
$$

for all distinct points $x, y \in X$ with $y \leq x$ where $\psi:[0, \infty) \rightarrow[0, \infty)$ is a lower semicontinuous function with the property that $\psi(t)=0$ if and only if $t=0$, and

$$
M(x, y)=\max \left\{\frac{d(x, T x) d(y, T y)}{d(x, y)}, d(x, y)\right\} .
$$

Also, assume either

(i) $T$ is continuous or

(ii) if $\left\{x_{n}\right\}$ is a non-decreasing sequence in $X$ such that $x_{n} \rightarrow x$, then $x=\sup \left\{x_{n}\right\}$.

If there exists $x_{0} \in X$ such that $x_{0} \leq T x_{0}$, then $T$ has a fixed point.

Set $\Phi=\{\phi \mid \phi:[0, \infty) \rightarrow[0, \infty)$ is continuous and non-decreasing with $\phi(t)=0$ if and only if $t=0\}$ and $\Psi=\{\psi \mid \psi:[0, \infty) \rightarrow[0, \infty)$ is lower semi continuous, $\psi(t)>0$ for all $t>0$, and $\psi(0)=0$ \}. For some work on the class of $\Phi$ or the class of $\Psi$, we refer the reader to $[21,51,54]$.

In 2004, Berinde [55] introduced an almost contraction, a new class of contractive type mappings which exhibits totally different features more than the one of the particular results incorporated $[1,16,39,50]$, i.e., an almost contraction generally does not have a unique fixed point; see Example 1 in [55]. Thereafter, many authors presented several interesting and useful facts about almost contractions; see [42, 56-59].

The purpose of this article is to generalize the above results for a mapping $T: X \rightarrow X$ involving a generalized $(\phi, \psi)$-almost contraction. Some examples are also presented to show that our results are effective.

\section{Main result}

Our essential result is given as follows.

Theorem 3 Let $(X, \leq)$ be a partially ordered set. Suppose there exists a metric $d$ such that $(X, d)$ is a complete metric space. Let $T: X \rightarrow X$ be a non-decreasing mapping which satisfies the inequality

$$
\begin{aligned}
\phi(d(T x, T y)) \leq & \phi(M(x, y))-\psi(M(x, y)) \\
& +L \min \{d(x, T y), d(y, T x), d(x, T x), d(y, T y)\}
\end{aligned}
$$

for all distinct points $x, y \in X$ with $y \leq x$ where $\phi \in \Phi, \psi \in \Psi, L \geq 0$ and

$$
M(x, y)=\max \left\{\frac{d(x, T x) d(y, T y)}{d(x, y)}, d(x, y)\right\} .
$$

Also, assume either

(i) $T$ is continuous or

(ii) if $\left\{x_{n}\right\}$ is a non-decreasing sequence in $X$ such that $x_{n} \rightarrow x$, then $x=\sup \left\{x_{n}\right\}$.

If there exists $x_{0} \in X$ such that $x_{0} \leq T x_{0}$, then $T$ has a fixed point. 
Proof Let $x_{0} \in X$ such that $x_{0} \leq T x_{0}$. We define a sequence $\left\{x_{n}\right\}$ in $X$ as follows:

$$
x_{n}=T x_{n-1} \quad \text { for } n \geq 1 \text {. }
$$

Since $T$ is a non-decreasing mapping together with (2.2), we have $x_{2}=T x_{1}$. Inductively, we obtain

$$
x_{0} \leq x_{1} \leq x_{2} \leq \cdots \leq x_{n-1} \leq x_{n} \leq x_{n+1} \leq \cdots .
$$

Assume that there exists $n_{0}$ such that $x_{n_{0}}=x_{n_{0}+1}$. Since $x_{n_{0}}=x_{n_{0}+1}=T x_{n_{0}}$, then $T$ has a fixed point. Suppose that $x_{n} \neq x_{n+1}$ for all $n \in \mathbb{N}$. Thus, by (2.3) we have

$$
x_{0}<x_{1}<x_{2}<\cdots<x_{n-1}<x_{n}<x_{n+1}<\cdots .
$$

Regarding (2.4), the condition (2.1) implies that

$$
\begin{aligned}
\phi\left(d\left(x_{n}, x_{n+1}\right)\right)= & \phi\left(d\left(T x_{n-1}, T x_{n}\right)\right) \\
\leq & \phi\left(M\left(x_{n-1}, x_{n}\right)\right)-\psi\left(M\left(x_{n-1}, x_{n}\right)\right) \\
& +L \min \left\{d\left(x_{n-1}, T x_{n}\right), d\left(T x_{n-1}, x_{n}\right), d\left(x_{n-1}, T x_{n-1}\right), d\left(x_{n}, T x_{n}\right)\right\} \\
\leq & \phi\left(M\left(x_{n-1}, x_{n}\right)\right)-\psi\left(M\left(x_{n-1}, x_{n}\right)\right) \\
& +L \min \left\{d\left(x_{n-1}, x_{n+1}\right), d\left(x_{n}, x_{n}\right), d\left(x_{n-1}, x_{n}\right), d\left(x_{n}, x_{n+1}\right)\right\} \\
= & \phi\left(M\left(x_{n-1}, x_{n}\right)\right)-\psi\left(M\left(x_{n-1}, x_{n}\right)\right),
\end{aligned}
$$

where

$$
\begin{aligned}
M\left(x_{n-1}, x_{n}\right) & =\max \left\{\frac{d\left(x_{n-1}, T x_{n-1}\right) d\left(x_{n}, T x_{n}\right)}{d\left(x_{n-1}, x_{n}\right)}, d\left(x_{n-1}, x_{n}\right)\right\} \\
& =\max \left\{d\left(x_{n}, x_{n+1}\right), d\left(x_{n-1}, x_{n}\right)\right\} .
\end{aligned}
$$

Suppose that $M\left(x_{n-1}, x_{n}\right)=d\left(x_{n}, x_{n+1}\right)$ for some $n \geq 1$. Then the inequality (2.5) turns into

$$
\phi\left(d\left(x_{n}, x_{n+1}\right)\right) \leq \phi\left(d\left(x_{n}, x_{n+1}\right)\right)-\psi\left(d\left(x_{n}, x_{n+1}\right)\right) .
$$

Regarding (2.4) and the property of $\psi$, this is a contradiction. Thus, $M\left(x_{n-1}, x_{n}\right)=$ $d\left(x_{n-1}, x_{n}\right)$ for all $n \geq 1$. Therefore, the inequality (2.5) yields

$$
\phi\left(d\left(x_{n}, x_{n+1}\right)\right) \leq \phi\left(d\left(x_{n-1}, x_{n}\right)\right)-\psi\left(d\left(x_{n-1}, x_{n}\right)\right)<\phi\left(d\left(x_{n-1}, x_{n}\right)\right) .
$$

Since $\phi$ is non-decreasing, we have $d\left(x_{n}, x_{n+1}\right) \leq d\left(x_{n-1}, x_{n}\right)$. Consequently, $\left\{d\left(x_{n-1}, x_{n}\right)\right\}$ is a decreasing sequence of positive real numbers which is bounded below. So, there exists $\alpha \geq 0$ such that $\lim _{n \rightarrow \infty} d\left(x_{n-1}, x_{n}\right)=\alpha$. We claim that $\alpha=0$. Suppose, to the contrary, that $\alpha>0$. By taking the limit of the supremum in the relation $\phi\left(d\left(x_{n}, x_{n+1}\right)\right) \leq \phi\left(d\left(x_{n-1}, x_{n}\right)\right)-$ $\psi\left(d\left(x_{n-1}, x_{n}\right)\right)$, as $n \rightarrow \infty$, we get

$$
\phi(\alpha) \leq \phi(\alpha)-\psi(\alpha)<\phi(\alpha)
$$


which is a contradiction. Hence, we conclude that $\alpha=0$, that is,

$$
\lim _{n \rightarrow \infty} d\left(x_{n-1}, x_{n}\right)=0
$$

We prove that the sequence $\left\{x_{n}\right\}$ is Cauchy in $X$. Suppose, to the contrary, that $\left\{x_{n}\right\}$ is not a Cauchy sequence. So, there exists $\varepsilon>0$ such that

$$
d\left(x_{m(k)}, x_{n(k)}\right) \geq \varepsilon
$$

where $\left\{x_{m(k)}\right\}$ and $\left\{x_{n(k)}\right\}$ are subsequences of $\left\{x_{n}\right\}$ with

$$
n(k)>m(k) \geq k
$$

Moreover, $n(k)$ is chosen to be the smallest integer satisfying (2.8). Thus, we have

$$
d\left(x_{m(k)}, x_{n(k)-1}\right)<\varepsilon .
$$

By the triangle inequality, we get

$$
\begin{aligned}
\varepsilon & \leq d\left(x_{m(k)}, x_{n(k)}\right) \leq d\left(x_{m(k)}, x_{n(k)-1}\right)+d\left(x_{n(k)-1}, x_{n(k)}\right) \\
& <\varepsilon+d\left(x_{n(k)-1}, x_{n(k)}\right) .
\end{aligned}
$$

Keeping (2.7) in mind and letting $n \rightarrow \infty$ in the above inequality, we get

$$
\lim _{n \rightarrow \infty} d\left(x_{m(k)}, x_{n(k)}\right)=\varepsilon
$$

Due to the triangle inequality, we have

$$
d\left(x_{m(k)}, x_{n(k)}\right) \leq d\left(x_{m(k)}, x_{m(k)-1}\right)+d\left(x_{m(k)-1}, x_{n(k)-1}\right)+d\left(x_{n(k)-1}, x_{n(k)}\right)
$$

and

$$
d\left(x_{m(k)-1}, x_{n(k)-1}\right) \leq d\left(x_{m(k)-1}, x_{m(k)}\right)+d\left(x_{m(k)}, x_{n(k)}\right)+d\left(x_{n(k)}, x_{n(k)-1}\right) .
$$

By using (2.7), (2.11), and letting $n \rightarrow \infty$ in (2.12) and (2.13), we get

$$
\lim _{n \rightarrow \infty} d\left(x_{m(k)-1}, x_{n(k)-1}\right)=\varepsilon
$$

Analogously, we derive

$$
\lim _{n \rightarrow \infty} d\left(x_{m(k)}, x_{n(k)-1}\right)=\varepsilon \quad \text { and } \quad \lim _{n \rightarrow \infty} d\left(x_{m(k)-1}, x_{n(k)}\right)=\varepsilon .
$$

Since $m(k)<n(k)$ we have $x_{m(k)-1}<x_{n(k)-1}$. By (2.1) we have

$$
\begin{aligned}
& \phi\left(d\left(x_{m(k)}, x_{n(k)}\right)\right) \\
& \quad=\phi\left(d\left(T x_{m(k)-1}, T x_{n(k)-1}\right)\right)
\end{aligned}
$$




$$
\begin{aligned}
\leq & \phi\left(M\left(x_{m(k)-1}, x_{n(k)-1}\right)\right)-\psi\left(M\left(x_{m(k)-1}, x_{n(k)-1}\right)\right) \\
& +L \min \left\{d\left(x_{n(k)-1}, T x_{m(k)-1}\right), d\left(x_{m(k)-1}, T x_{n(k)-1}\right)\right. \\
& \left.d\left(x_{m(k)-1}, T x_{m(k)-1}\right), d\left(x_{n(k)-1}, T x_{n(k)-1}\right)\right\} \\
\leq & \phi\left(M\left(x_{m(k)-1}, x_{n(k)-1}\right)\right)-\psi\left(M\left(x_{m(k)-1}, x_{n(k)-1}\right)\right) \\
& +L \min \left\{d\left(x_{n(k)-1}, x_{m(k)}\right), d\left(x_{m(k)-1}, x_{n(k)}\right), d\left(x_{m(k)-1}, x_{m(k)}\right), d\left(x_{n(k)-1}, x_{n(k)}\right)\right\}
\end{aligned}
$$

where

$$
\begin{aligned}
M & \left(x_{m(k)-1}, x_{n(k)-1}\right) \\
& =\max \left\{\frac{d\left(x_{m(k)-1}, T x_{m(k)-1}\right) d\left(x_{n(k)-1}, T x_{n(k)-1}\right)}{d\left(x_{m(k)-1}, x_{n(k)-1}\right)}, d\left(x_{m(k)-1}, x_{n(k)-1}\right)\right\} \\
& =\max \left\{\frac{d\left(x_{m(k)-1}, x_{m(k)}\right) d\left(x_{n(k)-1}, x_{n(k)}\right)}{d\left(x_{m(k)-1}, x_{n(k)-1}\right)}, d\left(x_{m(k)-1}, x_{n(k)-1}\right)\right\} .
\end{aligned}
$$

Letting $n \rightarrow \infty$ in (2.16) (and hence in (2.17)), and taking (2.7), (2.11), (2.14), and (2.15) into account, we obtain

$$
\phi(\varepsilon) \leq \phi(\max \{0, \varepsilon\})-\psi(\max \{0, \varepsilon\})+L \min \{\varepsilon, \varepsilon, 0,0\}<\phi(\varepsilon),
$$

which is a contradiction. Thus, $\left\{x_{n}\right\}$ is a Cauchy sequence in $X$. Since $X$ is a complete metric space, there exists $z \in X$ such that $\lim _{n \rightarrow \infty} x_{n}=z$.

We will show that $z$ is a fixed point of $T$. Assume that (i) holds. Then by the continuity of $T$, we have

$$
z=\lim _{n \rightarrow \infty} x_{n}=\lim _{n \rightarrow \infty} T x_{n-1}=T\left(\lim _{n \rightarrow \infty} x_{n-1}\right)=T z .
$$

Suppose that (ii) holds. Since $\left\{x_{n}\right\}$ is a non-decreasing sequence and $\lim _{n \rightarrow \infty} x_{n}=z$ then $z=\sup \left\{x_{n}\right\}$. Hence, $x_{n} \leq z$ for all $n \in \mathbb{N}$. Since $T$ is a non-decreasing mapping, we conclude that $T x_{n} \leq T z$, or equivalently,

$$
x_{n} \leq x_{n+1} \leq T z \quad \text { for all } n \in \mathbb{N} \text {. }
$$

Then $z=\sup \left\{x_{n}\right\}$, and we get $z \leq T z$.

To this end, we construct a new sequence $\left\{y_{n}\right\}$ as follows:

$$
y_{0}=z \quad \text { and } \quad y_{n}=T y_{n-1} \quad \text { for all } n \geq 1 .
$$

Since $z \leq T z$, we have $y_{0} \leq T y_{0}=y_{1}$. Hence we find that $\left\{y_{n}\right\}$ is a non-decreasing sequence. By repeating the discussion above, one can conclude that $\left\{y_{n}\right\}$ is Cauchy. Thus there exists $y \in X$ such that $\lim _{n \rightarrow \infty} y_{n}=y$. By (ii), we have $y=\sup \left\{y_{n}\right\}$ and so we have $y_{n} \leq y$. From (2.19), we get

$$
x_{n}<z=y_{0} \leq T z=T y_{0} \leq y_{n} \leq y \quad \text { for all } n \in \mathbb{N} .
$$


If $z=y$ then the proof is finished. Suppose that $z \neq y$. On account of (2.20), the expression (2.1) implies that

$$
\begin{aligned}
\phi\left(d\left(x_{n+1}, y_{n+1}\right)\right)= & \phi\left(d\left(T x_{n}, T y_{n}\right)\right) \\
\leq & \phi\left(M\left(x_{n}, y_{n}\right)\right)-\psi\left(M\left(x_{n}, y_{n}\right)\right) \\
& +L \min \left\{d\left(x_{n}, T y_{n}\right), d\left(y_{n}, T x_{n}\right), d\left(x_{n}, T x_{n}\right), d\left(y_{n}, T y_{n}\right)\right\} \\
\leq & \phi\left(M\left(x_{n}, y_{n}\right)\right)-\psi\left(M\left(x_{n}, y_{n}\right)\right) \\
& +L \min \left\{d\left(x_{n}, y_{n+1}\right), d\left(y_{n}, x_{n+1}\right), d\left(x_{n}, x_{n+1}\right), d\left(y_{n}, y_{n+1}\right)\right\},
\end{aligned}
$$

where

$$
\begin{aligned}
M\left(x_{n}, y_{n}\right) & =\max \left\{\frac{d\left(x_{n}, T x_{n}\right) d\left(y_{n}, T y_{n}\right)}{d\left(x_{n}, y_{n}\right)}, d\left(x_{n}, y_{n}\right)\right\} \\
& =\max \left\{\frac{d\left(x_{n}, x_{n+1}\right) d\left(y_{n}, y_{n+1}\right)}{d\left(x_{n}, y_{n}\right)}, d\left(x_{n}, y_{n}\right)\right\} .
\end{aligned}
$$

Letting $n \rightarrow \infty$ in (2.21) (and hence (2.22)), we obtain

$$
\phi(d(y, z)) \leq \phi(d(y, z))-\psi(d(y, z))<\phi(d(y, z))
$$

which is a contradiction. So $y=z$ and we have $z \leq T z \leq z$, then $T z=z$.

If we take $L=0$ in Theorem 3 we get the following result.

Theorem 4 Let $(X, \leq)$ be a partially ordered set. Suppose there exists a metric $d$ such that $(X, d)$ is a complete metric space. Let $T: X \rightarrow X$ be a non-decreasing mapping which satisfies the inequality

$$
\phi(d(T x, T y)) \leq \phi(M(x, y))-\psi(M(x, y))
$$

for all distinct $x, y \in X$ with $y \leq x$ where $\phi \in \Phi, \psi \in \Psi$ and

$$
M(x, y)=\max \left\{\frac{d(x, T x) d(y, T y)}{d(x, y)}, d(x, y)\right\} .
$$

Also, assume either

(i) $T$ is continuous or

(ii) if $\left\{x_{n}\right\}$ is a non-decreasing sequence in $X$ such that $x_{n} \rightarrow x$, then $x=\sup \left\{x_{n}\right\}$.

If there exists $x_{0} \in X$ such that $x_{0} \leq T x_{0}$, then $T$ has a fixed point.

Other corollaries could be derived.

Corollary 5 Let $(X, \leq)$ be a partially ordered set. Suppose there exists a metric d such that $(X, d)$ is a complete metric space. Let $T: X \rightarrow X$ be a non-decreasing mapping such that

$$
d(T x, T y) \leq M(x, y)-\psi(M(x, y))+L \min \{d(x, T y), d(y, T x), d(x, T x), d(y, T y)\}
$$


for all distinct $x, y \in X$ with $y \leq x$ where $\psi \in \Psi, L \geq 0$ and

$$
M(x, y)=\max \left\{\frac{d(x, T x) d(y, T y)}{d(x, y)}, d(x, y)\right\} .
$$

Also, assume either

(i) $T$ is continuous or

(ii) if $\left\{x_{n}\right\}$ is a non-decreasing sequence in $X$ such that $x_{n} \rightarrow x$, then $x=\sup \left\{x_{n}\right\}$.

If there exists $x_{0} \in X$ such that $x_{0} \leq T x_{0}$, then $T$ has a fixed point.

Proof Take $\phi(t)=t$ in Theorem 3 .

Corollary 6 Let $(X, \leq)$ be a partially ordered set. Suppose there exists a metric $d X$ such that $(X, d)$ is a complete metric space. Let $T: X \rightarrow X$ be a non-decreasing mapping such that

$$
d(T x, T y) \leq k M(x, y)+L \min \{d(x, T y), d(y, T x), d(x, T x), d(y, T y)\},
$$

for all distinct $x, y \in X$ with $y \leq x$ where $L \geq 0$ and

$$
M(x, y)=\max \left\{\frac{d(x, T x) d(y, T y)}{d(x, y)}, d(x, y)\right\} .
$$

Also, assume either

(i) $T$ is continuous or

(ii) if $\left\{x_{n}\right\}$ is a non-decreasing sequence in $X$ such that $x_{n} \rightarrow x$, then $x=\sup \left\{x_{n}\right\}$.

If there exists $x_{0} \in X$ such that $x_{0} \leq T x_{0}$, then $T$ has a fixed point.

Proof Take $\psi(t)=(1-k) \psi(t)$ for all $t \in[0, \infty)$ in Corollary 5 .

Corollary 7 Let $(X, \leq)$ be a partially ordered set. Suppose there exists a metric $d$ such that $(X, d)$ is a complete metric space. Let $T: X \rightarrow X$ be a non-decreasing mapping such that

$$
d(T x, T y) \leq \alpha \frac{d(x, T x) d(y, T y)}{d(x, y)}+\beta d(x, y)
$$

for all distinct $x, y \in X$ with $y \leq x$ where $\alpha, \beta \in[0,1)$ with $\alpha+\beta<1$. Also, assume either

(i) $T$ is continuous or

(ii) if $\left\{x_{n}\right\}$ is a non-decreasing sequence in $X$ such that $x_{n} \rightarrow x$, then $x=\sup \left\{x_{n}\right\}$.

If there exists $x_{0} \in X$ such that $x_{0} \leq T x_{0}$, then $T$ has a fixed point.

Proof Take $L=0$ and $k=\alpha+\beta$ for all $t \in[0, \infty)$ in Corollary 6. Indeed,

$$
\begin{aligned}
d(T x, T y) & \leq \alpha \frac{d(x, T x) d(y, T y)}{d(x, y)}+\beta d(x, y) \\
& \leq(\alpha+\beta) \max \left\{\frac{d(x, T x) d(y, T y)}{d(x, y)}, d(x, y)\right\} .
\end{aligned}
$$


Theorem 8 In addition to the hypotheses of Theorem 3, assume that

for every $x, y \in X$ there exists $z \in X$ that is comparable to $x$ and $y$,

then Thas a unique fixed point.

Proof Suppose, to the contrary, that $x$ and $y$ are fixed points of $T$ where $x \neq y$. By (2.28), there exists a point $z \in X$ which is comparable with $x$ and $y$. Without loss of generality, we choose $z \leq x$. We construct a sequence $\left\{z_{n}\right\}$ as follows:

$$
z_{0}=z \quad \text { and } \quad z_{n}=T z_{n-1} \quad \text { for all } n \geq 1 .
$$

Since $T$ is non-decreasing, $z \leq x$ implies $T z \leq T x=x$. By induction, we get $z_{n} \leq x$.

If $x=z_{N_{0}}$ for some $N_{0} \geq 1$ then $z_{n}=T z_{n-1}=T x=x$ for all $n \geq N_{0}-1$. So $\lim _{n \rightarrow \infty} z_{n}=x$. Analogously, we get $\lim _{n \rightarrow \infty} z_{n}=y$, which completes the proof.

Consider the other case, that is, $x \neq z_{n}$ for all $n=0,1,2, \ldots$ Then, by (2.1), we observe that

$$
\begin{aligned}
\phi\left(d\left(x, z_{n}\right)\right)= & \phi\left(d\left(T x, T z_{n-1}\right)\right) \\
\leq & \phi\left(M\left(x, z_{n-1}\right)\right)-\psi\left(M\left(x, z_{n-1}\right)\right) \\
& +L \min \left\{d(x, T x), d\left(z_{n-1}, T z_{n-1}\right), d\left(x, T z_{n-1}\right), d\left(z_{n-1}, T z_{n-1}\right)\right\} \\
= & \phi\left(M\left(x, z_{n-1}\right)\right)-\psi\left(M\left(x, z_{n-1}\right)\right)
\end{aligned}
$$

for all distinct $x, y \in X$ with $y \leq x$ where $\phi \in \Phi, \psi \in \Psi$ and

$$
\begin{aligned}
M\left(x, z_{n-1}\right) & =\max \left\{\frac{d(x, T x) d\left(z_{n-1}, T z_{n-1}\right)}{d\left(x, z_{n-1}\right)}, d\left(x, z_{n-1}\right)\right\} \\
& =\max \left\{\frac{d(x, x) d\left(z_{n-1}, z_{n}\right)}{d\left(x, z_{n-1}\right)}, d\left(x, z_{n-1}\right)\right\} \\
& =d\left(x, z_{n-1}\right) .
\end{aligned}
$$

Thus,

$$
\phi\left(d\left(x, z_{n}\right)\right) \leq \phi\left(d\left(x, z_{n-1}\right)\right)-\psi\left(d\left(x, z_{n-1}\right)\right)<\phi\left(d\left(x, z_{n}\right)\right)
$$

which is a contradiction. This ends the proof.

\section{Remark}

- Corollary 5 is a generalization of Theorem 2.1 of Luong and Thuan [4].

- Corollary 7 (with $L=0$ ) corresponds to Theorem 2.2 and Theorem 2.3 of Harjani, López and Sadarangani [3].

- Theorem 2.28 generalizes Theorem 2.4 of Luong and Thuan [4].

Now, we give some examples illustrating our results. 
Example 9 Let $X=\{4,5,6\}$ be endowed with the usual metric $d(x, y)=|x-y|$ for all $x, y \in X$, and $\preceq:=\{(4,4),(5,5),(6,6),(6,4)\}$. Consider the mapping

$$
T=\left(\begin{array}{lll}
4 & 5 & 6 \\
4 & 6 & 4
\end{array}\right) .
$$

We define the functions $\phi, \psi:[0,+\infty) \rightarrow[0,+\infty)$ by $\phi(t)=2 t$ and $\psi(t)=\frac{3}{2} t$. Now, we will check that all the hypotheses required by Theorem 4 (Theorem 3 with $L=0$ ) are satisfied.

First, $X$ has the property: if $\left\{x_{n}\right\}$ is a non-decreasing sequence in $X$ such that $x_{n} \rightarrow x$, then $x=\sup \left\{x_{n}\right\}$. Indeed, let $\left\{z_{n}\right\}$ be a non-decreasing sequence in $X$ with respect to $\preceq$ such that $z_{n} \rightarrow z \in X$ as $n \rightarrow+\infty$. We have $z_{n} \preceq z_{n+1}$ for all $n \in \mathbb{N}$.

- If $z_{0}=4$, then $z_{0}=4 \preceq z_{1}$. From the definition of $\preceq$, we have $z_{1}=4$. By induction, we get $z_{n}=4$ for all $n \in \mathbb{N}$ and $z=4$. Then $z_{n} \preceq z$ for all $n \in \mathbb{N}$ and $z=\sup \left\{z_{n}\right\}$.

- If $z_{0}=5$, then $z_{0}=5 \preceq z_{1}$. From the definition of $\preceq$, we have $z_{1}=5$. By induction, we get $z_{n}=5$ for all $n \in \mathbb{N}$ and $z=5$. Then $z_{n} \preceq z$ for all $n \in \mathbb{N}$ and $z=\sup \left\{z_{n}\right\}$.

- If $z_{0}=6$, then $z_{0}=6 \preceq z_{1}$. From the definition of $\preceq$, we have $z_{1} \in\{6,4\}$. By induction, we get $z_{n} \in\{6,4\}$ for all $n \in \mathbb{N}$. Suppose that there exists $p \geq 1$ such that $z_{p}=4$. From the definition of $\preceq$, we get $z_{n}=z_{p}=4$ for all $n \geq p$. Thus, we have $z=4$ and $z_{n} \preceq z$ for all $n \in \mathbb{N}$. Now, suppose that $z_{n}=6$ for all $n \in \mathbb{N}$. In this case, we get $z=6$ and $z_{n} \preceq z$ for all $n \in \mathbb{N}$ and $z=\sup \left\{z_{n}\right\}$.

Thus, we proved that in all cases, we have $z=\sup \left\{z_{n}\right\}$.

Let $x, y \in X$ such that $x \preceq y$ and $x \neq y$, so we have only $x=6$ and $y=4$. In particular

$$
d(T 6, T 4)=0 \quad \text { and } \quad M(6,4)=2 \text {, }
$$

so (2.23) holds easily. On the other hand, it is obvious that $T$ is a non-decreasing mapping with respect to $\preceq$ and there exists $x_{0}=6$ such that $x_{0} \preceq T x_{0}$. All the hypotheses of Theorem 4 are verified and $u=4$ is a fixed point of $T$.

Note that Theorem 1 is not applicable. Indeed, taking $x=4$ and $y=5$

$$
d(T 4, T 5)=2>\beta=\alpha \frac{d(4, T 4) d(5, T 5)}{d(4,5)}+\beta d(4,5),
$$

for any $\alpha, \beta \geq 0$ such that $\alpha+\beta<1$. Also, we could not apply Theorem 2 in this example. Indeed, for $x=6$ and $y=4$ (that is, $x \neq y$ and $x \preceq y$ ), we have

$$
0=d(T 6, T 4)>M(T 6, T 4)-\psi(M(T 6, T 4))=-1 .
$$

Example 10 Let $X=[0, \infty)$ be endowed with the Euclidean metric and the order $\preceq$ given as follows:

$$
x \preceq y \quad \Longleftrightarrow \quad(x=y) \text { or }(x, y \geq 1, x \leq y) .
$$

Define $T: X \rightarrow X$ by $T x=x$ if $0 \leq x<1$ and $T x=0$ if $x \geq 1$. Define the functions $\phi, \psi:$ $[0,+\infty) \rightarrow[0,+\infty)$ by $\phi(t)=4 t$ and $\psi(t)=3 t$.

Take $x \preceq y$ and $x \neq y$. It means that $1 \leq x<y$. In particular, $d(T x, T y)=0$ and $M(x, y)=$ $y-x$. This implies that (2.23) holds. It is easy that $X$ satisfies the property: if $\left\{x_{n}\right\}$ is a 
non-decreasing sequence in $X$ such that $x_{n} \rightarrow x$, then $x_{n} \preceq x$ for all $n \in \mathbb{N}$. Also, the other conditions of Theorem 4 are satisfied and $u=0$ is a fixed point of $T$.

Notice that we cannot apply Theorem 1 (since $T$ is not continuous) nor Theorem 2 to this example. Indeed, letting $x \preceq y$ and $x \neq y$ (that is, $1 \leq x<y$ ), we have

$$
d(T x, T y)=0>M(x, y)-\psi(M(x, y))=-2(y-x) .
$$

Example 11 Let $X=\{(0,1),(1,0),(1,1)\} \subset \mathbb{R}^{2}$ with the Euclidean distance $d_{2} .\left(X, d_{2}\right)$ is, obviously, a complete metric space. Moreover, we consider the order $\leq$ in $X$ given by $R=\{(x, x), x \in X\} \cup\{((0,1),(1,1))\}$. We also consider $T: X \rightarrow X$ given by $T((0,1))=(0,1)$, $T((1,0))=(1,0)$ and $T((1,1))=(0,1)$. Take $\phi(t)=3 t$ and $\psi(t)=2 t$. Obviously, $T$ is a continuous and non-decreasing mapping since $(0,1) \leq(1,1)$ and $T(0,1)=(0,1) \leq T(1,1)=(0,1)$. Let $x \leq y$ and $x \neq y$, then necessarily $x=(0,1)$ and $y=(1,1)$. Then

$$
d_{2}(T x, T y)=d_{2}((0,1),(0,1))=0 \quad \text { and } \quad M(x, y)=\sqrt{2} \text {, }
$$

so (2.23) holds. Also, $(0,1) \leq T((0,1))$, therefore all conditions in Theorem 4 hold and there are two fixed points which are $(0,1)$ and $(1,0)$. The non-uniqueness follows from the fact that the partial order $\leq$ is not total.

Note that Theorem 1 is not applicable. Indeed, taking $x=(0,1)$ and $y=(1,0)$

$$
d_{2}(T x, T y)=\sqrt{2}>(\alpha+\beta) \sqrt{2}=\alpha \frac{d_{2}(x, T x) d_{2}(y, T y)}{d_{2}(x, y)}+\beta d_{2}(x, y),
$$

for any $\alpha, \beta \geq 0$ such that $\alpha+\beta<1$. Also, we could not apply Theorem 2 in this example. Indeed, for $x=(0,1)$ and $y=(1,1)$ we have

$$
0=d_{2}(T x, T y)>\sqrt{2}-2 \sqrt{2}=M(x, y)-\psi(M(x, y)) .
$$

\section{Competing interests}

The authors declare that they have no competing interests.

\section{Authors' contributions}

All authors contributed equally and significantly in writing this article. All authors read and approved the final manuscript.

\section{Author details}

'Department of Mathematics, Statistics and Physics, Qatar University, Doha, Qatar. ${ }^{2}$ Department of Mathematics, Atilim University, Incek, Ankara 06836, Turkey. ${ }^{3}$ Nonlinear Analysis and Applied Mathematics Research Group (NAAM), King Abdulaziz University, Jeddah, Saudi Arabia. ${ }^{4}$ Permanent address: Institut Supérieur d'Informatique et des Technologies de Communication de Hammam Sousse, Université de Sousse, Route GP1-4011, Hammam Sousse, Tunisie. ${ }^{5}$ Present address: Department of Mathematics, College of Education of Jubail, P.O. Box 12020, Industrial Jubail, 31961, Saudi Arabia.

\section{Acknowledgements}

The authors express their gratitude to the referees for constructive and useful remarks and suggestions.

Received: 9 October 2013 Accepted: 15 May 2014 Published: 02 Jun 2014

\section{References}

1. Banach, S: Sur les opérations dans les ensembles abstraits et leur application aux équations intégrales. Fundam. Math. 3, 133-181 (1922)

2. Jaggi, DJ: Some unique fixed point theorems. Indian J. Pure Appl. Math. 8(2), $223-230$ (1977)

3. Harjani, J, López, B, Sadarangani, K: A fixed point theorem for mappings satisfying a contractive condition of rational type on a partially ordered metric space. Abstr. Appl. Anal. 2010, Article ID 190701 (2010)

4. Luong, NV, Thuan, NX: Fixed point theorem for generalized weak contractions satisfying rational expressions in ordered metric spaces. Fixed Point Theory Appl. 2011, Article ID 46 (2011) 
5. Agarwal, RA, El-Gebeily, MA, O'Regan, D: Generalized contractions in partially ordered metric spaces. Appl. Anal. 87, 109-116 (2008)

6. Amini-Harandi, A, Emami, H: A fixed point theorem for contraction type maps in partially ordered metric spaces and application to ordinary differential equations. Nonlinear Anal. 72, 2238-2242 (2010)

7. Altun, I, Simsek, H: Some fixed point theorems on ordered metric spaces and applications. Fixed Point Theory Appl. 2010, Article ID 621469 (2010)

8. Arshad, M, Karapınar, E, Jamshaid, A: Some unique fixed point theorems for rational contractions in partially ordered metric spaces. J. Inequal. Appl. 2013, Article ID 248 (2013)

9. Aydi, H: Fixed point results for weakly contractive mappings in ordered partial metric spaces. J. Adv. Math. Stud. 4(2), $1-12(2011)$

10. Aydi, $\mathrm{H}$ : Common fixed point results for mappings satisfying $(\psi, \phi)$-weak contractions in ordered partial metric spaces. Int. J. Math. Stat. 12(2), 63-64 (2012)

11. Aydi, H, Nashine, HK, Samet, B, Yazidi, H: Coincidence and common fixed point results in partially ordered cone metric spaces and applications to integral equations. Nonlinear Anal. 74(17), 6814-6825 (2011)

12. Aydi, H, Shatanawi, W, Postolache, M, Mustafa, Z, Tahat, N: Theorems for Boyd-Wong type contractions in ordered metric spaces. Abstr. Appl. Anal. 2012, Article ID 359054 (2012)

13. Aydi, $H$, Karapınar, E, Postolache, M: Tripled coincidence point theorems for weak $f$-contractions in partially ordered metric spaces. Fixed Point Theory Appl. 2012, Article ID 44 (2012)

14. Aydi, H, Postolache, $M$, Shatanawi, W: Coupled fixed point results for $(\psi, \phi)$-weakly contractive mappings in ordered G-metric spaces. Comput. Math. Appl. 63(1), 298-309 (2012)

15. Chandok, S, Karapınar, E: Common fixed point of generalized rational type contraction mappings in partially ordered metric spaces. Thai J. Math. 11(2), 251-260 (2013)

16. Chandok, S, Postolache, M: Fixed point theorem for weakly Chatterjea-type cyclic contractions. Fixed Point Theory Appl. 2013, Article ID 28 (2013)

17. Chandok, S, Mustafa, Z, Postolache, M: Coupled common fixed point theorems for mixed g-monotone mappings in partially ordered G-metric spaces. Sci. Bull. 'Politeh.' Univ. Buchar., Ser. A, Appl. Math. Phys. 75(4), 11-24 (2013)

18. Choudhury, BS, Metiya, N: Coincidence point and fixed point theorems in ordered cone metric spaces. J. Adv. Math. Stud. 5(2), 20-31 (2012)

19. Choudhury, BS, Metiya, N, Postolache, M: A generalized weak contraction principle with applications to coupled coincidence point problems. Fixed Point Theory Appl. 2013, Article ID 152 (2013)

20. Dey, D, Ganguly, A, Saha, M: Fixed point theorems for mappings under general contractive condition of integral type. Bull. Math. Anal. Appl. 3, 27-34 (2011)

21. Đorić, D: Common fixed point for generalized ( $\psi, \phi)$-weak contractions. Appl. Math. Lett. 22, 1896-1900 (2009)

22. Gnana Bhaskar, T, Lakshmikantham, V: Fixed point theorems in partially ordered metric spaces and applications. Nonlinear Anal. 65, 1379-1393 (2006)

23. Harjani, J, Sadarangani, K: Fixed point theorems for weakly contractive mappings in partially ordered sets. Nonlinear Anal. 71, 3403-3410 (2009)

24. Haghi, RH, Postolache, M, Rezapour, S: On T-stability of the Picard iteration for generalized $f$-contraction mappings. Abstr. Appl. Anal. 2012, Article ID 658971 (2012)

25. Ding, H-S, Li, L, Radenović, S: Coupled coincidence point theorems for generalized nonlinear contraction in partially ordered metric spaces. Fixed Point Theory Appl. 2012, Article ID 96 (2012)

26. Karapınar, E: Couple fixed point theorems for nonlinear contractions in cone metric spaces. Comput. Math. Appl. 59, 3656-3668 (2010)

27. Karapınar, E: Weak $\varphi$-contraction on partial metric spaces and existence of fixed points in partially ordered sets. Math. Aterna 1, 237-244 (2011)

28. Karapınar, E, Marudai, M, Pragadeeswarar, AV: Fixed point theorems for generalized weak contractions satisfying rational expression on a ordered partial metric space. Lobachevskii J. Math. 34(1), 116-123 (2013)

29. Nieto, JJ, Rodríguez-López, R: Contractive mapping theorems in partially ordered sets and applications to ordinary differential equations. Order 22, 223-239 (2005)

30. Miandaragh, MA, Postolache, M, Rezapour, S: Some approximate fixed point results for generalized $\alpha$-contractive mappings. Sci. Bull. 'Politeh.' Univ. Buchar., Ser. A, Appl. Math. Phys. 75(2), 3-10 (2013)

31. Miandaragh, MA, Postolache, M, Rezapour, S: Approximate fixed points of generalized convex contractions. Fixed Point Theory Appl. 2013, Article ID 255 (2013)

32. Abbas, M, Nazir, T, Radenović, S: Common fixed points of four maps in partially ordered metric spaces. Appl. Math Lett. 24, 1520-1526 (2011)

33. Abbas, M, Nazir, T, Radenović, S: Common coupled fixed points of generalized contractive mappings in partially ordered metric spaces. Positivity (2013). doi:10.1007/s11117-012-0219-z

34. Nieto, JJ, Rodríguez-López, R: Existence and uniqueness of fixed point in partially ordered sets and applications to ordinary differential equation. Acta Math. Sin. Engl. Ser. 23(12), 2205-2212 (2007)

35. O'Regan, D, Petrusel, A: Fixed point theorems for generalized contractions in ordered metric spaces. J. Math. Anal. Appl. 341, 1241-1252 (2008)

36. Olatinwo, MO, Postolache, M: Stability results for Jungck-type iterative processes in convex metric spaces. Appl. Math Comput. 218(12), 6727-6732 (2012)

37. Petrusel, A, Rus, IA: Fixed point theorems in ordered L-spaces. Proc. Am. Math. Soc. 134, 411-418 (2006)

38. Ran, ACM, Reurings, MVB: A fixed point theorem in partially ordered sets and some applications to matrix equations. Proc. Am. Math. Soc. 132, 1435-1443 (2004)

39. Rhoades, BE: A comparison of various definitions of contractive mappings. Trans. Am. Math. Soc. 226, 257-290 (1977)

40. Radenović, S, Kadelburg, Z, Jandrlić, A: Some results on weakly contractive maps. Bull. Iran. Math. Soc. 38(3), 625-645 (2012)

41. Radenović, S, Kadelburg, Z: Generalized weak contractions in partially ordered metric spaces. Comput. Math. Appl. 60, 1776-1783 (2010)

42. Shobkolaei, N, Sedghi, S, Roshan, JR, Altun, I: Common fixed point of mappings satisfying almost generalized $(S, T)$-contractive condition in partially ordered partial metric spaces. Appl. Math. Comput. 219, 443-452 (2012) 
43. Shatanawi, W, Postolache, M: Common fixed point results of mappings for nonlinear contractions of cyclic form in ordered metric spaces. Fixed Point Theory Appl. 2013, Article ID 60 (2013)

44. Shatanawi, W, Postolache, M: Some fixed point results for a G-weak contraction in G-metric spaces. Abstr. Appl. Anal. 2012, Article ID 815870 (2012)

45. Shatanawi, W, Postolache, M: Common fixed point theorems for dominating and weak annihilator mappings in ordered metric spaces. Fixed Point Theory Appl. 2013, Article ID 271 (2013)

46. Shatanawi, W, Postolache, M: Coincidence and fixed point results for generalized weak contractions in the sense of Berinde on partial metric spaces. Fixed Point Theory Appl. 2013, Article ID 54 (2013)

47. Shatanawi, W, Pitea, A: Fixed and coupled fixed point theorems of omega-distance for nonlinear contraction. Fixed Point Theory Appl. 2013, Article ID 275 (2013)

48. Shatanawi, W, Pitea, A: $\omega$-distance and coupled fixed point in G-metric spaces. Fixed Point Theory Appl. 2013, Article ID 208 (2013)

49. Shatanawi, W, Pitea, A: Some coupled fixed point theorems in quasi-partial metric spaces. Fixed Point Theory Appl. 2013, Article ID 153 (2013)

50. Zamfirescu, T: Fix point theorems in metric spaces. Arch. Math. 23, 292-298 (1972)

51. Zhang, Q, Song, Y: Fixed point theory for generalized $\phi$-weak contraction. Appl. Math. Lett. 22, 75-78 (2009)

52. Golubović, Z, Kadelburg, Z, Radenović, S: Common fixed points of ordered $g$-quasicontractions and weak contractions in ordered metric spaces. Fixed Point Theory Appl. 2012, Article ID 20 (2012)

53. Kadelburg, Z, Radenović, S, Pavlović, M: Common fixed point theorems for ordered contractions and quasicontractions in ordered cone metric spaces. Comput. Math. Appl. 59, 3148-3159 (2010)

54. Khan, KS, Swaleh, M, Sessa, S: Fixed point theorems for altering distances between the points. Bull. Aust. Math. Soc. 30(1), 1-9 (1984)

55. Berinde, V: Approximation fixed points of weak contractions using the Picard iteration. Nonlinear Anal. Forum 9 , 43-53 (2004)

56. Abbas, M, Vetro, P, Khan, SH: On fixed points of Berinde's contractive mappings in cone metric spaces. Carpath. J. Math. 26(2), 121-133 (2010)

57. Aghajani, A, Radenović, S, Roshan, JR: Common fixed point results for four mappings satisfying almost generalized $(S, T)$-contractive condition in partially ordered metric spaces. Appl. Math. Comput. 218, 5665-5670 (2012)

58. Babu, GVR, Sandhya, ML, Kameswari, MVR: A note on a fixed point theorem of Berinde on weak contraction. Carpath. J. Math. 24(1), 8-12 (2008)

59. Berinde, V: General constructive fixed point theorem for Ćirić-type almost contractions in metric spaces. Carpath. J. Math. 24(2), 10-19 (2008)

10.1186/1029-242X-2014-219

Cite this article as: Mustafa et al.: A discussion on generalized almost contractions via rational expressions in partially ordered metric spaces. Journal of Inequalities and Applications 2014, 2014:219

\section{Submit your manuscript to a SpringerOpen ${ }^{\odot}$ journal and benefit from:}

- Convenient online submission

Rigorous peer review

- Immediate publication on acceptance

- Open access: articles freely available online

- High visibility within the field

- Retaining the copyright to your article 